Abstracted/indexed in Academic Search Complete, Asia Journals Online, Bangladesh Journals Online, Biological Abstracts, BIOSIS Previews, CAB

Abstracts, Current Abstracts, Directory of Open Access Journals, EMBASE/Excerpta Medica, Google Scholar, HINARI (WHO), International

Pharmaceutical Abstracts, Open J-gate, Science Citation Index Expanded, SCOPUS and Social Sciences Citation Index;

ISSN: $1991-0088$

\title{
Intravenous caffeine versus intravenous ketorolac for the management of moderate to severe migraine headache
}

\author{
Alireza Baratloo', Sara Arab Bafarani', Mohammad Mehdi Forouzanfar', Behrooz \\ Hashemi' ${ }^{1}$ Benjamin Wolkin Friedman² and Ali Abdalvand3
}

${ }^{1}$ Department of Emergency Medicine, Shohadaye Tajrish Hospital, Shahid Beheshti University of Medical Sciences, Tehran, Iran; ${ }^{2}$ Department of Emergency Medicine, Albert Einstein College of Medicine, Montefiore Medical Center, Bronx, NY, USA; ${ }^{3}$ Department of Emergency Medicine, University of Calgary, Calgary, AB, Canada.

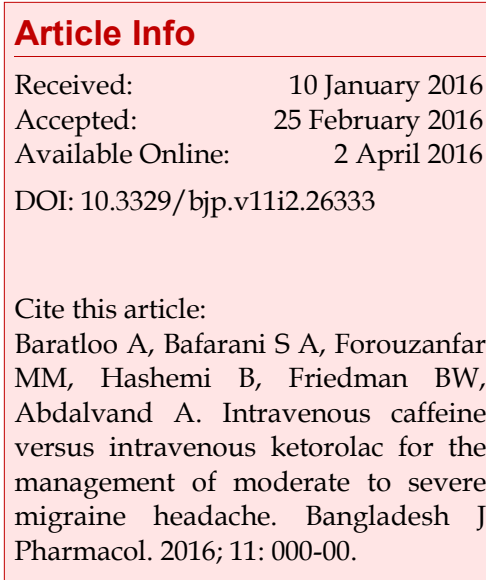

\begin{abstract}
The aim of this study was to determine if intravenous caffeine is as effective as intravenous ketorolac for the treatment of moderate to severe migraine headaches. Eligible patients randomly received $60 \mathrm{mg}$ caffeine citrate or 60 mg ketorolac infused intravenously. Their pain score were measured at baseline, one hour and two hours after infusion. Therapeutic success was defined as decreasing of at least 3 points on the pain score. In total 110 patients were enrolled (75.5\% women). Therapeutic success after $60 \mathrm{~min}$ was achieved by $63.6 \%$ of patients in the caffeine and $70.1 \%$ of patients in the ketorolac group $(\mathrm{p}=0.23)$. After $120 \mathrm{~min}, 87.3 \%$ of the caffeine group and $83.6 \%$ of the ketorolac group achieved therapeutic success $(p=0.49)$. In this multi-center, randomized double blind study, intravenous caffeine was as effective as intravenous ketorolac for first line abortive management of acute migraine.
\end{abstract}

\section{Introduction}

Migraine is a neurologic disorder that its prevalence is estimated as high as $17 \%$ in women and $6 \%$ in men and accounts for $1.3 \%$ of productive years lost due to medical disability (Natoli et al., 2010). Despite efforts to keep patients out of hospitals, migraine headaches are still sometimes managed in emergency departments and urgent care centers with intravenous medications. A large variety of agents are available for abortive migraine management in Emergency Department (ED). Ketorolac is a potent nonsteroidal anti-inflammatory drug (NSAID) that has been shown to be effective in this regard (Baratloo et al., 2016; Taggart et al., 2013). Despite its favorable effects, there are known side effects, contraindications and incomplete effectiveness. The search to find an alternative or adjunct medication has lead to the suggestion of caffeine for acute migraine management (Lipton et al., 1998; Pini et al., 2012). What makes caffeine attractive to conduct research is the fact that it has also been proposed to be one of the triggers for migraine headaches (Baratloo et al., 2015; Rogers et al., 2005). Parenteral caffeine has never been studied for acute migraine in a double blind fashion. This double blind clinical trial was designed to determine if intravenous caffeine is as effective as intravenous ketorolac in managing moderate to severe migraine headaches.

\section{Materials and Methods \\ Study design}

This double blind clinical trial was conducted in two tertiary care emergency departments in the city of Tehran, Iran. The goal of this study was to compare the effectiveness of caffeine versus ketorolac in managing migraine headaches. 


\section{Study population}

Sampling was conducted between January and December 2014 on patients admitted to the care centers who met international classification of headache disorders, $2^{\text {nd }}$ edition criteria for migraine for at least a year prior to the presentation day. Participants were between 18 and 65 years of age. Inclusion also required 2 episodes of headaches in the previous 3 months followed by a symptom free period or an episode of only mild symptoms. The following exclusion criteria were used to minimize confounding factors and to further homogenize the study population: Complex migraine, medication overuse headache, presence of other co-existing primary headaches (e.g. tension, cluster etc.). We also excluded patients for any of the following medication contra-indications: History of or current atrial or ventricular tachycardia, uncontrolled hypertension (defined as systolic BP $\geq 150 \mathrm{mmHg}$ ), ischemic heart disease, peptic ulcer disease, inflammatory bowel disease, obsessive compulsive disorders, pregnancy, lactation (nursing), coagulation disorders, renal or hepatic disease, sleep disorders, diabetes, respiratory disorders (asthma and COPD), drug or alcohol abuse and hypersensitivity to caffeine or ketorolac. Initially 193 patients were enrolled (Figure 1). Thirty four patients met at least one of the exclusion criteria. Forty nine patients refused to participate. Finally 110 patients were equally divided between the treatment groups- 55 in each study arm.

\section{Intervention}

Using an online random number generator, patients were assigned to $60 \mathrm{mg}$ of caffeine citrate in $100 \mathrm{~mL}$ of normal saline or to $60 \mathrm{mg}$ of ketorolac in $100 \mathrm{~mL}$ of normal saline. Each intervention was infused over 10 min. This dosage of caffeine was adopted from a previously published study to ensure safety and efficacy and to also avoid significant side effects (Baratloo et al., 2015). The ketorolac arm used manufacturer suggested dosages. For choosing the proper drug dosage, a meeting of academic neurologist, pharmacologist and emergency medicine experts was formed and the decision was made. Permuted randomization blocks without stratification were used in this study. Medication packages were prepared and packaged in identical thick plastic containers and were coded by an independent pharmacist. Thus, researchers, clinicians and patients were blinded to the intervention received. The medication packages were given to the study coordinators at each site. The name of the medication was only to be released if a serious side effect happened. In these cases the patient had to be excluded from the study and a treatment failure was supposed to be registered in the affected group. If the headache was not reasonably managed in the first 120 min after the end of the medication infusion, an attending physician was allowed to use an alternative medication such as a narcotic to treat the pain

\section{Outcome measures}

Data were collected by the chief resident at each site. Pain intensity was measured using a 10-point visual analog pain scale prior to medical intervention and then 60 and $120 \mathrm{~min}$ post medical intervention. The $120 \mathrm{~min}$ endpoint was chosen based on similar previous clinical trials, where $120 \mathrm{~min}$ was found to be standard (Coppola et al., 1995; Shahrami et al., 2015). Our primary outcome was therapeutic efficacy, which was defined as an improvement in three points on the visual analog scale without requirement of rescue medication. Patients were followed for 120 min from medication administration for observations of any side effects of the medication. Common side effects to be considered were tachycardia, hypertension, nausea, vomiting, site,

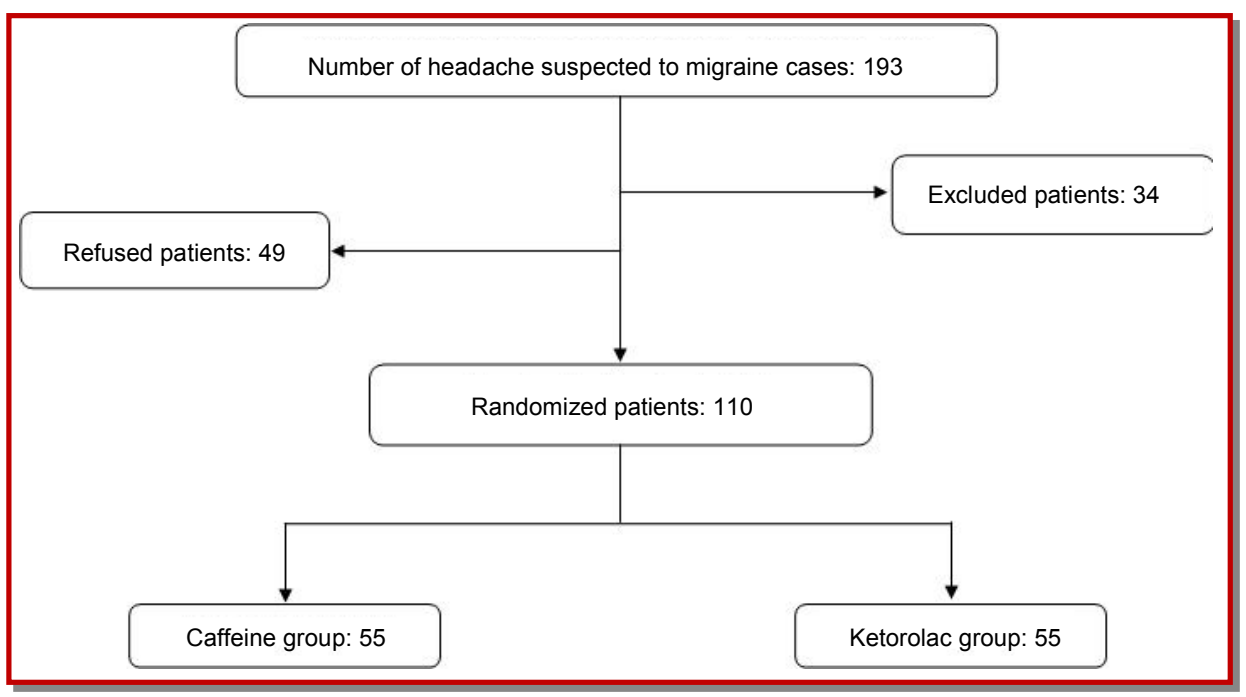

Figure 1: Enrolment of patients 
pruritus, agitation, restlessness and pain in the injection. Lastly, if patients experienced a significant decrease in their pain score (of at least three) and did not show any adverse effect, they were discharged from the department (Alschuler et al., 2012; Jensen et al., 2001; Kelly, 2001; Mark et al., 2009; Zelman et al., 2005). We also followed all patients after pain control to ensure the maintenance of at least 2 additional pain-free hours.

\section{Data analysis}

Sample size in this study was calculated based on the anticipated therapeutic successes of the caffeine group (44\%) and the ketorolac group (74\%) with $\alpha=0.05$ and $\beta$ $=0.1$. Using these parameters, sample size was calculated to be at least 51 per group. Data analysis was done by STATA version 11 software (Stata Corp. TX, USA). Since the data distribution was not normal $(\mathrm{p}<0.05$, based on Kolmogov-Smirnov test) the Mann-Whitney and Wilcoxon signed-rank test were used for ordinal pain score data. The Chi-square test and Fisher's exact test were used for dichotomous outcomes. A nonparametric (Wilcoxon-type) test for trend was used to compare the effect of the drugs in the first and the second $60 \mathrm{~min}$. Sub-group analyses for males versus females and for age groupings younger and older than 40 were also done. Therapeutic success was defined as a minimum of a three-point drop in the pain score and maintenance of at least a 2 hours pain-free period. In all analyses, $\mathrm{p}<0.05$ was considered statistically significant.

\section{Results}

Forty four $(80.0 \%)$ members of the caffeine group and $39(70.9 \%)$ members of the ketorolac group were female $(\mathrm{p}=0.27)$. The average ages in the caffeine and ketorolac groups were $30.3 \pm 8.6$ and $36.0 \pm 2.6$ years, respectively $(p=0.01)$.

The average pain score upon initial emergency department evaluation in the caffeine and ketorolac groups were $8.4 \pm 1.5$ in both groups $(\mathrm{p}=0.96)$. After $60 \mathrm{~min}$ post-intervention, pain scores were $5.4 \pm 1.5$ and $4.9 \pm$ 1.9 in the caffeine and ketorolac groups respectively ( $p$ $=0.23$ ). After $120 \mathrm{~min}$, pain scores were $3.5 \pm 2.6$ and 3.5 \pm 2.1 in the caffeine and ketorolac groups, respectively $(\mathrm{p}=0.49)$ (Table I).

Therapeutic success in the caffeine group was $63.6 \%$ after $60 \mathrm{~min}$ and $87.3 \%$ after $120 \mathrm{~min}$. The same measured variables were $70.1 \%$ and $83.6 \%$ in the ketorolac group respectively (Table II). While the therapeutic success in each group was statistically significantly different after 60 and 120 min when compared to baseline no statistically significant difference was found between the groups.

Fortunately, no patients suffered any of the aforementioned adverse effects. Sub-group analysis of the collected data did not reveal any age or sex dependent significant differences between the groups. All 83 patients who were not enrolled were treated with intravenous acetaminophen. Morphine sulfate was administered as a rescue medication.

\section{Table I}

\section{Comparison of mean reduction of pain scores between two groups after one and two hours}

\begin{tabular}{|l|ccccc|}
\hline & \multicolumn{2}{c}{ Ketorolac group } & \multicolumn{2}{c}{ Caffeine group } & p value \\
\cline { 2 - 5 } & $\begin{array}{c}\text { Mean and standard } \\
\text { deviation of pain } \\
\text { score }\end{array}$ & $\begin{array}{c}\text { Mean of declining of } \\
\text { pain score }\end{array}$ & $\begin{array}{c}\text { Mean and standard } \\
\text { deviation of pain } \\
\text { score }\end{array}$ & $\begin{array}{c}\text { Mean of declining of } \\
\text { pain score }\end{array}$ \\
On admission & $8.4 \pm 1.5$ & - & $8.4 \pm 1.5$ & - & $0.96^{\mathrm{a}}$ \\
After one hour & $4.9 \pm 1.9$ & $3.5 \pm 1.6$ & $5.4 \pm 2.4$ & $3.0 \pm 2.0$ & $0.23^{\mathrm{b}}$ \\
After two hours & $3.5 \pm 2.1$ & $4.9 \pm 2.3$ & $3.5 \pm 2.6$ & $4.9 \pm 2.2$ & $0.49^{\mathrm{b}}$ \\
\hline
\end{tabular}

aBased on Mann-Whitney test; bBased on Wilcoxon rank test

Table II

Comparison of success rate between groups after one and two hours

\begin{tabular}{|lccccc|}
\hline & \multicolumn{2}{c}{ Ketorolac group } & \multicolumn{2}{c}{ Caffeine group } & P-value \\
\cline { 2 - 5 } & Success rate & $95 \%$ Confidence interval & Success rate & $95 \%$ Confidence interval & \\
After one hour & 70.1 & $57.9-81.2$ & 63.6 & $50.4-75.1$ & $0.42^{\mathrm{a}}$ \\
After two hours & 83.6 & $71.7-91.1$ & 87.3 & $76.0-93.7$ & $0.59 \mathrm{a}$ \\
\hline
\end{tabular}

aBased on non-parametric (Wilcoxon-type) test for trend 


\section{Discussion}

In this randomized, double-blind multi-center EDbased study, we have demonstrated that intravenous caffeine is as efficacious as intravenous ketorolac for the acute treatment of migraine. Ideally, treatment for migraine headaches should be safe, fast and effective. An optimal treatment should have minimum side effects and must decrease the odds of recurrence. To this day, we have yet to find a treatment regimen that contains all of these qualities simultaneously. Studies in this field are still underway. The present study shows that caffeine and ketorolac have similar therapeutic success in controlling the pain in moderate to severe migraine headaches.

While there have been studies conducted on the effects of these two drugs on migraine headaches, to our knowledge this study is the first of its kind to perform a head to head comparison of caffeine and ketorolac. In a meta-analysis, Tagart et al., examined the effects of ketorolac on decreasing the pain intensity of severe headaches in adults. They found that ketorolac has therapeutic effects on this type of headache that are comparable to standard treatment regimens. Therefore, these authors recommended ketorolac as a second line therapy in these cases (Taggart et al., 2013). In a randomized study not included in the meta-analysis, Friedman et al., reported similar findings in regards to the effectiveness of ketorolac in managing migraine headaches - a decrease in pain scale scores of 3.9 units (Friedman et al., 2014). Meredith et al., compared the effectiveness of sumatriptan and ketorolac on emergency department migraine management, finding the latter to be more effective (Meredith et al., 2003).

We were unable to identify any randomized studies of intravenous caffeine. Goldstein et al., showed in a study that oral combinations containing caffeine are faster and more potent compared to ibuprofen in the ED management of migraines (Goldstein et al., 2014). In another study by Di Monda et al., a caffeine containing cocktail (indomethacin, prochlorperazine and caffeine) was found to be superior to sumatriptan in the management of acute migraines (Monda et al., 2003).

We only followed patients during their ED stay. A longer follow-up period would have revealed the frequency of recurrence of symptoms after caffeine and ketorolac. Another limitation to this study is the lack of a placebo arm. Although including a placebo arm would have provided useful data, doing so is hard to ethically justify, given that patients admitted to the emergency department would not receive any pain management for at least $120 \mathrm{~min}$. Since the 30\% noninferiority margin that we prospectively defined based on previous published data was a rather subjective number. Although we found caffeine to be non-inferior to ketorolac in acute migraine management, this study was under-powered to show a non-inferiority of this margin size and the conclusions need to be made cautiously.

\section{Conclusion}

Caffeine is as effective as ketorolac and can be a reasonable first line abortive medication in emergency department management of acute migraine.

\section{Ethical Issue}

The sampling phase was performed after final approval was received from the ethics committee of the Shahid Beheshti University of Medical Sciences. Patients were enrolled to this study voluntarily after giving informed consent. The declaration of helsinki ethical principles were followed and respected throughout the study. The study was conducted using the manual of the "International Conference on Harmonization of Guidelines for Good Clinical Practice". The study protocol is available at Www.IRCT.IR with the registration number IRCT2013120315640N1.

\section{Conflict of Interest}

All authors declare that there is no conflict of interest in this study.

\section{Acknowledgement}

We would like to express our special thanks to Dr. Mahmoud Yousefifard for his invaluable helps. This study was conducted with a grant from the Clinical Research Development Center of Shohadaye Tajrish Hospital. This study was a part of Dr. Sara Arab Bafarani thesis as an emergency medicine resident at Shahid Beheshti University of Medical Sciences, Tehran, Iran.

\section{References}

Alschuler KN, Jensen MP, Ehde DM. Defining mild, moderate, and severe pain in persons with multiple sclerosis. Pain Med. 2012; 13: 1358-65.

Baratloo A, Amiri M, Forouzanfar MM, Hasani S, Fouda S, Negida A. Efficacy measurement of ketorolac in reducing the severity of headache. J Emerg Pract Trauma. 2016; 2: 21-24.

Baratloo A, Negida A, El-Ashal G, Behnaz N. Intravenous caffeine for the treatment of acute migraine: A pilot study. J Caffeine Res. 2015; 5: 125-29.

Baratloo A, Rouhipour A, Forouzanfar MM, Safari S, Amiri M, Negida A. The role of caffeine in pain management: A brief literature review. Anesthesiol Pain Med. 2015; (in press).

Coppola M, Yealy DM, Leibold RA. Randomized, placebocontrolled evaluation of prochlorperazine versus metoclopramide for emergency department treatment of migraine headache. Ann Emerg Med. 1995; 26: 541-46. 
Friedman BW, Garber L, Yoon A, Solorzano C, Wollowitz A, Esses D, Gallagher EJ. Randomized trial of IV valproate vs metoclopramide vs ketorolac for acute migraine. Neurology 2014; 82: 976-83.

Goldstein J, Hagen M, Gold M. Results of a multicenter, double-blind, randomized, parallel-group, placebo-controlled, single-dose study comparing the fixed combination of acetaminophen, acetylsalicylic acid and caffeine with ibuprofen for acute treatment of patients with severe migraine. Cephalalgia 2014; 34: 1070-78.

Jensen MP, Smith DG, Ehde DM, Robinsin LR. Pain site and the effects of amputation pain: Further clarification of the meaning of mild, moderate and severe pain. Pain 2001; 91: $317-22$.

Kelly A. The minimum clinically significant difference in visual analogue scale pain score does not differ with severity of pain. Emerg Med J. 2001; 18: 205-07.

Lipton RB, Stewart WF, Ryan, RE, Saper J, Silberstein S, Sheftell F. Efficacy and safety of acetaminophen, aspirin and caffeine in alleviating migraine headache pain: Three double -blind, randomized, placebo-controlled trials. Arch Neurol. 1998; 55: 210-17.

Mark M, Au T, Choi Y, Wong T. The minimum clinically significant difference in visual analogue scale pain score in a local emergency setting. Hong Kong J Emerg Med. 2009; 16: 233-36.

Meredith JT, Wait S, Brewer KL. A prospective double-blind study of nasal sumatriptan versus IV ketorolac in migraine. Am J Emerg Med. 2003; 21: 173-75.
Monda VD, Nicolodi M, Aloisio A, Bianco PD, Fonzari M, Grazioli I, Sicuteri F. Efficacy of a fixed combination of indomethacin, prochlorperazine and caffeine versus sumatriptan in acute treatment of multiple migraine attacks: A multicenter, randomized, cross-over trial. Headache J Head Face Pain. 2003; 43: 835-44.

Natoli JL, Manack A, Dean B, Butler Q, Turkel CC, Stovner L, Lipton, RB. Global prevalence of chronic migraine: A systematic review. Cephalalgia 2010; 30: 599-609.

Pini LA, Guerzoni S, Cainazzo M, Ciccarese M, Prudenzano MP, Livrea P. Comparison of tolerability and efficacy of a combination of paracetamol + caffeine and sumatriptan in the treatment of migraine attack: A randomized, doubleblind, double-dummy, cross-over study. J Headache Pain. 2012; 13: 669-75.

Rogers NL, Dinges DF. Caffeine: Implications for alertness in athletes. Clinics Sports Med. 2005; 24: 1-13.

Shahrami A, Assarzadegan F, Hatamabadi HR, Asgarzadeh M, Sarehbandi B, Asgarzadeh S. Comparison of therapeutic effects of magnesium sulfate vs. dexamethasone/metoclopramide on alleviating acute migraine headache. J Emerg Med. 2015; 48: 69-76.

Taggart E, Doran S, Kokotillo A, Campbell S, Villa-Roel C, Rowe $\mathrm{BH}$. Ketorolac in the treatment of acute migraine: A systematic review. Headache J Head Face Pain. 2013; 53: 27787.

Zelman DC, Dukes E, Brandenburg N, Bostrom A, Gore M. Identification of cut-points for mild, moderate and severe pain due to diabetic peripheral neuropathy. Pain 2005; 115: 29-36. 


\section{Your feedback about this paper}

1. Number of times you have read this paper 0

2. Quality of paper
Excellent
Good
Moderate
Not good

3. Your comments

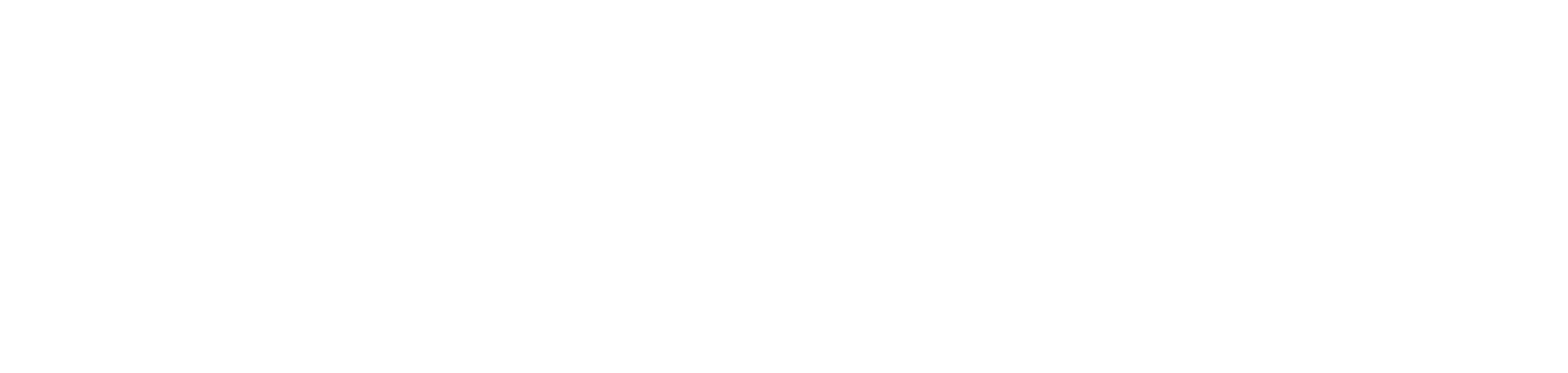

